\title{
Effects of different osmolarities on bacterial biofilm formation
}

\author{
Vanessa Nessner Kavamura, Itamar Soares de Melo
}

Laboratório de Microbiologia Ambiental, Embrapa Meio Ambiente, Jaguariúna, SP, Brazil.

Submitted: March 14, 2013; Approved: September 9, 2013.

\begin{abstract}
Biofilm formation depends on several factors. The influence of different osmolarities on bacterial biofilm formation was studied. Two strains (Enterobacter sp. and Stenotrophomonas sp.) exhibited the most remarkable alterations. Biofilm formation is an important trait and its use has been associated to the protection of organisms against environmental stresses.
\end{abstract}

Key words: bacteria, biofilm formation, $\mathrm{NaCl}$, D-sorbitol.

\section{Introduction}

Biofilm is defined as a matrix of microbial population adherent to each other and/or to surfaces and interfaces. Extracellular compounds, such as carbohydrates, proteins and even DNA (Branda et al., 2005; Costerton et al., 1995), compose this matrix. Biofilm, besides its role in supporting cells against physical forces, also helps in their survival against stress conditions such as the effect of antimicrobial compounds (Park and Fuqua, 2004). It also protects its constituents against plants defense mechanisms when attacked by pathogens (Walker et al., 2004), helps the colonization of phytopathogens by blocking the flow of nutrients (Newman et al., 2003) and protects against desiccation and other types of environmental stresses (Danhorn and Fuqua, 2007; Monier and Lindow, 2003). Biofilm formation is triggered by unfavorable external conditions that modify the expression of several genes. Biofilm, in turn, alters the microenvironment of its inhabitants that leading to alteration of gene expression and maturation of biofilm and so on (Jefferson, 2004). In the present study we tested whether different osmolarities influence bacterial biofilm formation.

Soil samples were obtained from the rhizosphere of Cereus jamacaru, a native cactus from the Caatinga biome of Northeast of Brazil. Bacteria were isolated in Tryptone Soya Agar (TSA) (10\%) medium and nine strains were tested for biofilm formation. Bacterial genomic DNA was extracted according to Sunnucks and Hales (1996). The 16S rRNA gene was amplified by polymerase chain reaction (PCR) using universal primers 1492R (5-TAC GGY
TAC CTT GTT ACG ACT-3) and 27F (5-GAG AGT TTG ATC CTG GCT CAG-3). Samples were purified using $1.5 \mu \mathrm{L}$ of an enzyme mix containing the ratio of $2 \mu \mathrm{L}$ of Fast-Ap (Fermentas) for $0.8 \mu \mathrm{L}$ of Exonuclease I (Fermentas). The samples were submitted for $15 \mathrm{~min}$ to $37^{\circ} \mathrm{C}$ and then $5 \mathrm{~min}$ at $80^{\circ} \mathrm{C}$. Sequencing was achieved using ABI 3500 Genetic Analyzer (Applied Biosystems). Phylogenetic relationship based on partial 16S rRNA gene sequence of bacterial strains was performed with comparison to EZ-Taxon database (Kim et al., 2012). Alignment was constructed using ClustalW (Thompson et al., 1994), followed by clustering using Neighbor-Joining distance and Jukes-Cantor model (Jukes and Cantor, 1969) with a bootstrap analysis of 1,000 replicates (Felsenstein, 1985) in Mega 5.01 (Tamura et al., 2011).

The method used to detect the formation of biofilm was based on the methodology described by O'Toole and Kolter (1998) with modifications. The method relies on the ability of cells to adhere to the walls of polypropylene $1.5 \mathrm{~mL}$ tubes. To each tube, $100 \mu \mathrm{L}$ from an overnight bacterial culture was added to $900 \mu \mathrm{L}$ of culture media Tryptone Soya Broth (TSB) (10\%) supplemented with D-sorbitol and $\mathrm{NaCl}$ at different concentrations $(0.03,0.06,0.3$ and $0.6 \mathrm{M}$ of D-sorbitol and $0.015,0.03,0.15$ and $0.3 \mathrm{M}$ of $\mathrm{NaCl})$. After inoculation, the tubes were incubated at $40{ }^{\circ} \mathrm{C}$ for $72 \mathrm{~h}$. After this stage, the content of each tube was aspirated with an automatic hand pipette and the tubes were washed three times with $1000 \mu \mathrm{L}$ of sterilized distilled water in order to remove the non-adherent cells. The water was removed and the tubes were left to dry and then $1000 \mu \mathrm{L}$ of 
$0.1 \%$ crystal violet (CV) were added for $15 \mathrm{~min}$. The CV was removed and the tubes were washed again three times with $1000 \mu \mathrm{L}$ of sterilized distilled water in order to remove the excess of dye. To quantify biofilm formation $1000 \mu \mathrm{L}$ of $95 \%$ ethanol was added to each tube to solubilize the $\mathrm{CV}$-dyed tube. The absorbance was determined with a spectrophotometer (UV- visible spectrophotometer: UV$1601 \mathrm{PC}$, Shimadzu) at $560 \mathrm{~nm}$. Before the addition of CV, the cells were homogenized by an automatic hand pipette to quantify bacterial growth at $600 \mathrm{~nm}$. The values were obtained in absorbance - optical density (OD), being biofilm formation considered as $\mathrm{OD}_{560}$ and growth as $\mathrm{OD}_{600}$. Biofilm formation was considered for $\mathrm{OD}_{560} \geq 0.1$, in a scale of weak formation $\left(0.1 \leq \mathrm{OD}_{560}<0.2\right)$ and medium formation $\left(0.2 \leq \mathrm{OD}_{560}<0.5\right)$. The experiments were all performed in triplicate. Data were subjected to One-Way ANOVA followed by a classification of means with Tukey's test at $5 \%$, using the software Assistat 7.6 beta (Silva and Azevedo, 2002).

The relationship among the nine strains used in this study is shown in Figure 1. Phylogenetic analysis assigned five isolates to several species of the genus Bacillus (clade I) and four to the Phylum Proteobacteria (clade II).

The addition of $\mathrm{NaCl}$ has significantly induced the growth of three strains (LMArzc55, LMArzc158 and LMArzc189). The remaining six strains grew well in all four concentrations. The addition of D-sorbitol had a greater influence than $\mathrm{NaCl}$ on the growth of strains. Two strains (LMArzc17 and LMArzc40) grew equally in all four concentrations. LMArzc158 grew significantly better with $0.6 \mathrm{M}$ of D-sorbitol and strains LMArzc189 and LMArzc324 showed better growth with 0.3 and $0.6 \mathrm{M}$ of D-sorbitol. Four strains (LMArzc55, LMarzc108, LMArzc192 and LMArzc214) were inhibited by the addition of D-sorbitol, with better growth within the two first concentrations.

Only three concentrations of D-sorbitol added to the TSB medium significantly affected biofilm formation of all isolates tested. The lowest concentration of sorbitol $(0.03 \mathrm{M})$ did not affect significantly biofilm formation. However, concentrations of $0.06 \mathrm{M}, 0.30 \mathrm{M}$ and $0.6 \mathrm{M}$ of D-sorbitol had a significant effect on the production of biofilm, with strain LMArzc17 exhibiting the best characteristic in all three concentrations, ranging from medium to weak formation $\left(\mathrm{OD}_{560}=0.21,0.12\right.$ and 0.16 , respectively).

Concerning the formation of biofilm, Table 1 shows the biofilm formation by the nine strains in all conditions. With $0.015 \mathrm{M}$ of $\mathrm{NaCl}$, two strains (LMArzc17 and LMArzc 189) were able to form significantly more biofilm than others $(0.01 \leq \mathrm{p}<0.05)$, with $\mathrm{OD}_{560}$ of 0.20 and 0.21 , respectively. Only LMArzc 189 formed statistically more biofilm with the addition of $0.03 \mathrm{M}$ of $\mathrm{NaCl}$ than the other strains $\left(\mathrm{OD}_{560}=0.25\right)$. The two last concentrations did not promote any significant difference in biofilm formation among all strains, and some of them showed a slight production or none.

In a general way, biofilm formation was influenced by different osmolarities, being more frequent in two strains: LMArzc17 and LMArzc189 and their growth and biofilm formation are shown in detail in Figure 2.

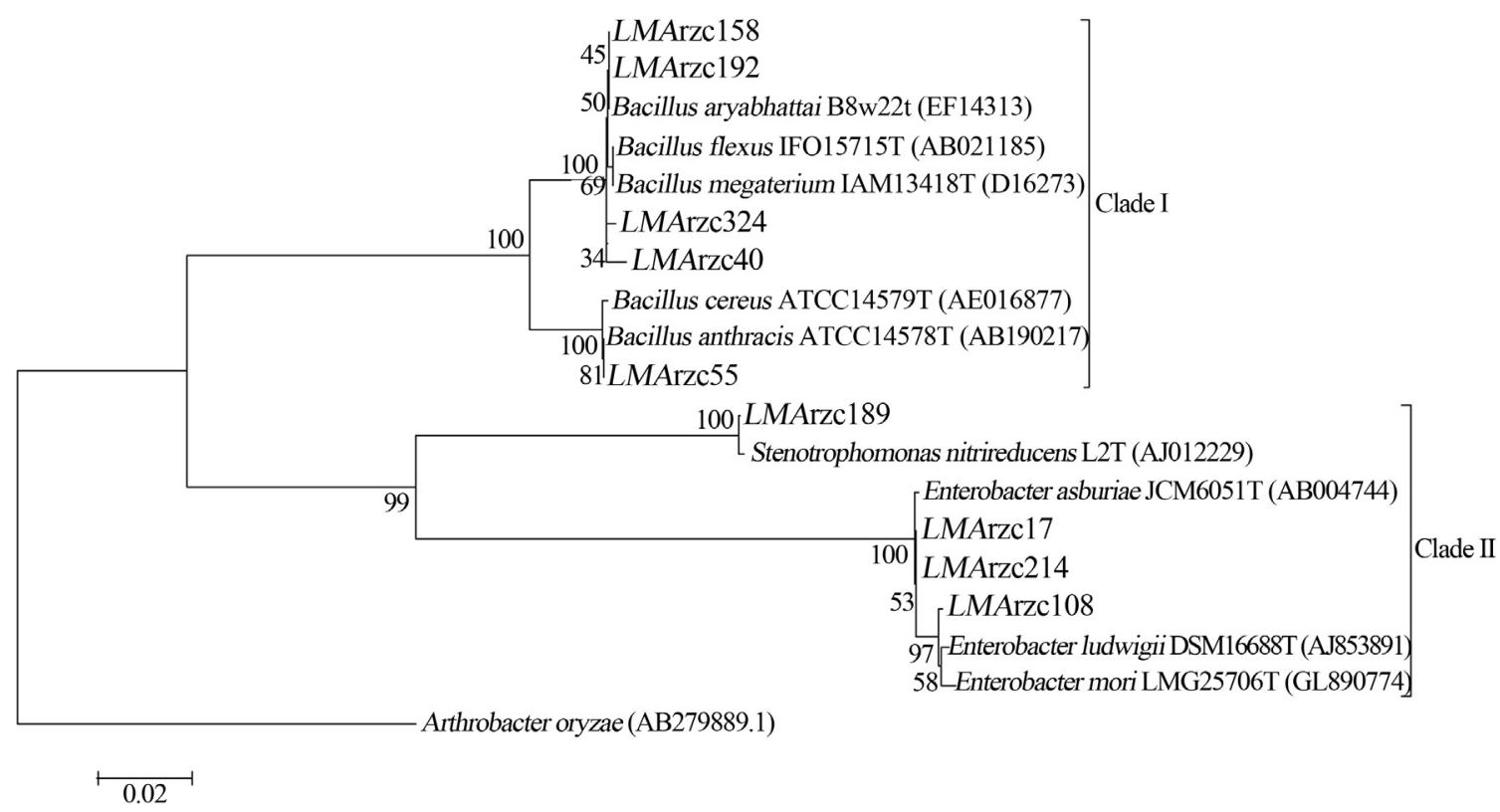

Figure 1 - Neighbor-joining tree based on 16S rRNA partial gene, with phylogenetic relationship between nine isolates belonging to Firmicutes (clade I) and Proteobacteria (clade II). The scale bar at the bottom indicates the number of differences in base composition among sequences. Bootstrap for 1,000 replicates. Arthrobacter oryzae was used as an outgroup. 

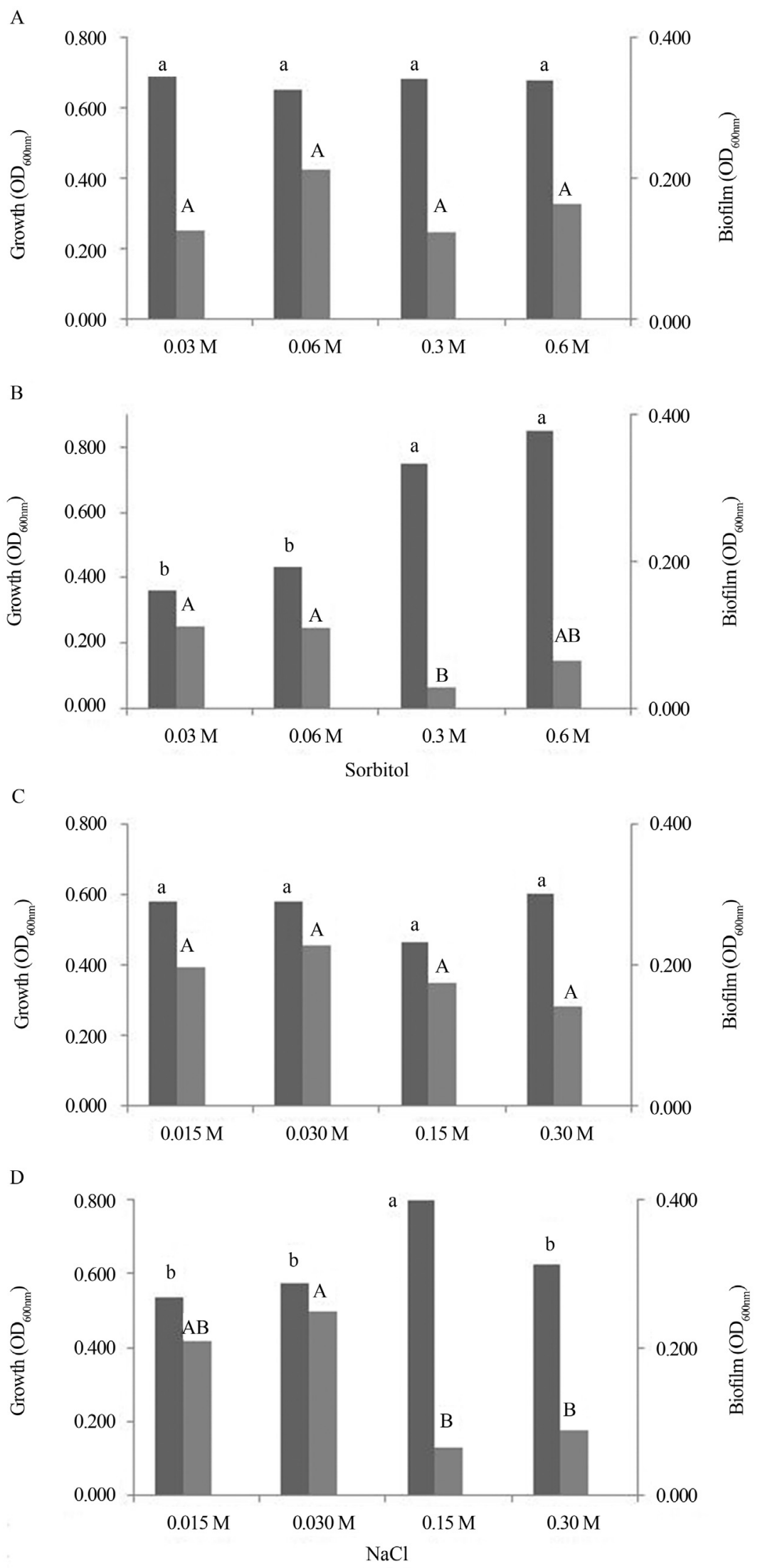

Figure 2 - Growth and biofilm formation by two strains: LMArzc17 (A and C) and LMArzc189 (B and D) with sorbitol or NaCl, both in four different concentrations. Means followed by different letters with the same size are statistically different from each other according to Tukey's test at $5 \%$. 
Table 1 - Biofilm formation as follows: weak formation $\left(0.1 \leq \mathrm{OD}_{560}<0.2\right)(+)$, average formation $\left(0.2 \leq \mathrm{OD}_{560}<0.5\right)(++)$, no formation $(-)$.

\begin{tabular}{|c|c|c|c|c|c|c|c|c|}
\hline \multirow[t]{2}{*}{ Strains } & \multicolumn{4}{|c|}{ D-sorbitol (M) } & \multicolumn{4}{|c|}{$\mathrm{NaCl}(\mathrm{M})$} \\
\hline & 0.03 & 0.06 & 0.3 & 0.6 & 0.015 & 0.03 & 0.15 & 0.3 \\
\hline LMArzc17 & + & $++^{*}$ & $+*$ & $+*$ & $++*$ & ++ & + & + \\
\hline LMArzc40 & - & - & - & - & + & - & + & + \\
\hline LMArzc55 & - & + & - & - & + & - & - & - \\
\hline LMArzc108 & + & - & - & - & + & + & + & + \\
\hline LMArzc158 & - & - & - & - & - & + & - & - \\
\hline LMArzc189 & + & + & - & - & $++*$ & $++*$ & - & - \\
\hline LMArzc192 & - & - & - & - & - & - & - & + \\
\hline LMArzc 214 & + & - & + & - & + & + & + & - \\
\hline LMArzc324 & - & - & - & - & + & + & - & + \\
\hline
\end{tabular}

$(*)$ - Statistically significant differences at $5 \%$.

Khan et al. (2011) suggested that the biofilm formation can be induced by certain substances. Morikawa et al. (2006) observed an increase in the production of biofilm by B. subtilis with increased concentration of $\mathrm{Mn}^{2+}$ and glycerol added to the culture medium. According to Hallsworth et al. (1998), glycerol and sorbitol when added to any medium or solution, reduces the water activity of this medium. We have observed weak to average biofilm formation by Enterobacter spp. and Bacillus spp. Biofilm formation by Enterobacteriaceae species is reported for E. sakazakii (Lehner et al., 2005) and other species (Hurrel et al., 2009).

As discussed earlier, the formation of exopolysaccharides (EPS) provides cellular protection against adverse environmental conditions and also contributes to biofilm formation (Chang et al., 2007; Wai et al., 1998). More recently, Seminara et al. (2012) observed that the production of EPS is crucial for spreading B. subtilis biofilm. The biofilm, in turn, may assist in root colonization during plant growth (Ramey et al., 2004) and can also protect cells from nutrient deprivation, changes in $\mathrm{pH}$, oxygen free radicals, antibiotics, phagocytosis (Jefferson, 2004) and water-limiting conditions (Chang et al., 2007). Some EPS are highly hydrated due to the incorporation of water into its structure through hydrogen bonds, which could prevent desiccation in some biofilms (Flemming et al., 2000). In this way, the verification of biofilm formation is an interesting feature because it can assist in many processes. In this study we concluded that the formation of biofilm is influenced by different concentrations of solutes added to the medium and we observed a significant production in two strains similar to Enterobacter sp. and Stenotrophomonas sp.

\section{References}

Branda SS, Vik S, Friedman L, Kolter R (2005) Biofilms: The matrix revisited. Trends Microbiol 13:20-26.

Chang WS, van de Mrotel M, Nielsen L, Guzman GN, Li X, Halverson LJ (2007) Alginate production by Pseudomonas putida creates a hydrated microenvironment and contributes to biofilm architecture and stress tolerance under waterlimiting conditions. J Bacteriol 189:8290-8299.

Costerton JW, Lewandowski Z, Caldwell DE, Korber DR, Lappin-Scott HM (1995). Microbial biofilms. Annu Rev Microbiol 49:711-745.

Danhorn T, Fuqua C (2007) Biofilm formation by plantassociated bacteria. Annu Rev Microbiol 61:401-422.

Felsenstein J (1985) Confidence limits on phylogenies: An approach using the bootstrap. Evolution 39:783-791.

Flemming HCJ, Wingender G, Mayer C, (2000) Physico-chemical properties of biofilms. In: Evans, L.V. (ed). Biofilms: Recent advances in their study and control. Harwood Academic Publishers, Amsterdam, pp 19-34.

Hallsworth JE, Nomura Y, Iwahara M (1998) Ethanol-induced water stress and fungal growth. J Ferm Bioeng 86:451-456.

Hurrell E, Kucerova E, Loughlin M, Caubilla-Barron J, Forsythe SJ (2009) Biofilm formation on enteral feeding tubes by Cronobacter sakazakii, Salmonella serovars and Enterobacteriaceae. Int J Food Microbiol 136:227-231.

Jefferson KK (2004) What drives bacteria to produce biofilm? FEMS Microbiol Lett 236:163-173.

Jukes TH, Cantor CR, (1969) Evolution of protein molecules. In: Munro, H.N. (ed). Mammalian Protein Metabolism. Academic Press, New York, pp 21-132.

Khan N, Mishra A, Chauhan PS, Nautiyal CS (2011) Induction of Paenibacillus lentimorbus biofilm by sodium alginate and $\mathrm{CaCl}_{2}$ alleviates drought stress in chickpea. Ann Appl Biol 159:371-386.

Kim OS, Cho YJ, Lee K, Yoon SH, Kim M, Na H, Park SC, Jeon YS, Lee JH, Yi H, Won S, Chun J (2012) Introducing EzTaxon-e: A prokaryotic 16S rRNA Gene sequence database with phylotypes that represent uncultured species. Int J Syst Evol Microbiol 62:716-721.

Lehner A, Riedel K, Eberl L, Breeuwer P, Diep B, Stephan R (2005) Biofilm formation, extracellular polysaccharide production, and cell-to-cell signaling in various Enterobacter sakazakii strains: Aspects promoting environmental persistence. J Food Prot 68:2287-2294.

Monier JM, Lindow SE (2003) Differential survival of solitary and aggregated bacterial cells promote aggregate formation on leaf surfaces. PNAS 100:15077-15982. 
Morikawa M, Kagihiro S, Haruki M, Takano K, Branda S, Kolter R, Kanaya S (2006) Biofilm formation by a Bacillus subtilis strain that produces $\gamma$-polyglutamate. Microbiol 152:28012807.

Newman KL, Almeida RPP, Purcell AH, Lindow SE (2003) Use of a green fluorescent strain for analysis of Xylella fastidiosa colonization of Vitis vinifera. Appl Environ Microbiol 69:7319-7327.

O'Toole GA, Kolter R (1998) Initiation of biofilm formation in Pseudomonas fluorescens WCS365 proceeds via multiple, convergent signalling pathways: A genetic analysis. Mol Microbiol 28:449-461.

Parsek MR, Fuqua C (2004) Biofilms 2003: Emerging themes and challenges in studies of surface-associated microbial life. $\mathrm{J}$ Bacteriol 186:4427-4440.

Ramey BE, Koutsoudis M, von Bodman SB, Fuqua C (2004) Biofilm formation in plant-microbe associations. Curr Opin Microbiol 7:602-609.

Seminara A, Angelini TE, Wilking JN, Vlamakis H, Ebrahim S, Kolter R, Weitz DA, Brenner MP (2012) Osmotic spreading of Bacillus subtilis biofilms driven by an extracellular matrix. PNAS 109:1116-1121.

Silva FAS, Azevedo CAV (2002) Versão do programa computacional Assistat para o sistema operacional Windows. Rev Bras Prod Agroind 4:71-78.
Sunnucks P, Hales DF (1996) Numerous transposed sequences of mitochondrial cytochrome oxidase I-II in aphids of the genus Sitobion (Hemiptera: Aphididae). Mol Biol Evol 13:510-524.

Tamura K, Peterson D, Peterson N, Stecher G, Nei M, Kumar S (2011) MEGA5: Molecular evolutionary genetics analysis using maximum likelihood, evolutionary distance, and maximum parsimony methods. Mol Biol Evol 28:2731-2739.

Thompson JD, Higgins DG, Gibson TJ (1994) CLUSTAL W: Improving the sensitivity of progressive multiple sequence alignment through sequence weighting, position specific gap penalties and weight matrix choice. Nucleic Acids Res 22:4673-4680.

Wai SN, Mizunoe Y, Takade A, Kawabata SI, Yoshida SI (1998) Vibrio cholera O1 strain TSI-4 produces the exopolysaccharide materials that determine colony morphology, stress resistance, and biofilm formation. Appl Environ Microbiol 64:3648-3655.

Walker TS, Bais HP, Deziel E, Schweizer HP, Rahme LG, et al. (2004) Pseudomonas aeruginosa-plant root interactions. Pathogenicity, biofilm formation, and root exudation. Plant Physiol 134:320-331.

All the content of the journal, except where otherwise noted, is licensed under a Creative Commons License CC BY-NC. 